\title{
The Doctor's Heart: A Qualitative Study Exploring Physicians' Views on Their Professional Performance in Light of Excellence, Humanistic Practice and Accountability
}

Myra van den Goor ( $\square$ m.vandengoor@q3consult.nl )

Acadamic Medical Center https://orcid.org/0000-0002-6361-0178

Benjamin Boerebach

Sint Antonius Ziekenhuis

Elisa Bindels

AMC

Maas Jan Heineman

AMC

Kiki Lombarts

AMC

Research article

Keywords: Physician performance, professional values, professional development, reflective practice, humanistic practice

Posted Date: May 4th, 2020

DOI: https://doi.org/10.21203/rs.3.rs-22857/v1

License: @ (i) This work is licensed under a Creative Commons Attribution 4.0 International License. Read Full License 


\section{Abstract}

Background In a field as high-stakes as health care, professional values have long been recognized as an essential mediating force for good medical practice. In the current era of changing market forces, anchoring these values in the professional performance of daily practice can be challenging. In this study we explored how physicians reflect upon their own professional performance and whether they feel they are performing to their best ability in light of excellence, humanistic practice and accountability.

Methods We conducted a thematic analysis of written reflections from 786 hospital-based physicians, representing 35 specialties and 18 hospitals.

Results When reflecting on their professional performance, physicians differentiated between (i) their calling for being a doctor, (ii) the translation of this calling into daily practice, and (iii) threats to their performance. Reflecting on humanistic practice triggered thoughts about the essence of being a physician in terms of calling, meaning and purpose. Physicians described concrete actions regarding pursuit of excellence and accountability. Furthermore, they suggested that their ability to perform optimally was put under pressure, mainly by heavy workloads and collaboration issues. This pressure negatively affected their calling for being a doctor and hampered the ability to be a humanistic practitioner.

Conclusions In this large inventory of reflections, humanistic practice was recognized as the core value of being a physician. However, physicians feel high performance and the ability to act as a humanistic practitioner is hindered by heavy workloads and collaboration issues. Decreasing the clinical burden and reinforcing humanistic and relational aspects of care could foster an environment where physicians can perform optimally.

\section{Background}

In a field as complex and as high-stakes as health care, professional values have long been recognized as an essential mediating force in patient care [1,2]. The often implicit ideas about physicians' performance are made explicit in a variety of charters and guidelines, all having roots extending back to the classic and oldest of all codes of conduct: the Hippocratic Oath $[3,4$,$] . The Hippocratic Oath has survived as an ideal for almost$ 2500 years, inspiring physicians to reinvent and uphold valued ethical principles regarding their performance [5]. These ethical principles capture the essence of being a physician and are described in characteristics such as quality of care (excellence, lifelong learning, competence), quality of caring (compassion, empathy, respect), integrity, and accountability $[1,6,7,8]$. Many documents translate these values into more hands-on guidelines and formulate good medical practice in concrete terms of knowledge, skills, communication, teamwork and maintaining trust and safety $[9,10,11]$. At the most practical level, competence frameworks describe the knowledge, skills and abilities that physicians should have in order to provide high quality patient care $[12,13]$.

Defining professional performance is complex since it encompasses all the aforementioned perspectives ranging from values to actual competences. Incorporating all these elements leads to definitions of professional performance as 'a physician committed to the health and well-being of individuals and society through ethical practice, profession-led regulation, and high personal standards of behaviour' [14]. From a 
more practical perspective, physician performance can be viewed as 'that what physicians are actually seen to do in practice', being a reflection of their adherence to values and the necessary skills and competences [15].

With the abovementioned in mind, an integrated model for physicians' professional performance was developed in The Netherlands by Kiki Lombarts [15]. In her view, high performance is a reflection of physicians' commitment to three pillars of professional performance: (i) constantly pursuing excellence, (ii) humanistic practice and, (iii) being accountable for one's professional actions. Additionally, she argues that physicians can only sustainably provide high quality patient care if and when their commitment to these three pillars of performance is anchored in the underlying professional values of the medical profession.

Displaying the desired commitments to the three pillars and practicing professional values in daily practice can be a challenge. Moreover, changes in healthcare systems and settings may actually hamper physicians' ability to perform to their highest possible levels. For example, further marketization of healthcare encourages a shift in focus to productivity and efficiency [16,17], and increased administrative workloads may result in less face-to-face time with patients $[17,18,19]$. These aspects often result in physicians lacking time, energy or inspiration, and can translate into the diminished commitment to essential professional values and of professional performance. In light of these and many other challenges to physicians' performance, it is in the interest of patients and society that physicians are able and are enabled to act according to their professional values. In this study, we were interested in hearing first-hand from hospital-based physicians about whether they felt they were performing to the best of their ability.

Therefore, the aim of our study was to gain insight into physicians' perspectives on their own professional performance. This multicentre study used written reflections of nearly 800 physicians of multiple specialties. Our research question was: how do physicians reflect upon their professional performance in terms of the pursuit of excellence, humanistic practice, and accountability?

\section{Methods}

\section{Setting and participants}

We conducted this study in the Netherlands, where physicians are either employed by hospitals or organized in independent entrepreneur partnerships. All licensed physicians must periodically demonstrate that they are up to date and fit to practice for recertification as a physician, being the equivalent of revalidation in the United Kingdom or maintenance of certification in the USA $[9,20,21]$. In this mandatory process in The Netherlands, physicians gather feedback from multiple colleagues and also self-assess and reflect on their performance. To guide the assessment and reflection, an assessment tool including a few reflective questions based on the three performance pillars as described in the introduction was provided [22]. The reflections were for personal use only and were not shared with colleagues, managers or the revalidation authority. For this study, we used physicians' reflections on their performance, as written in the context of their recertification process.

Participants were all hospital-based physicians, representing various specialties from several (academic and non-academic) hospitals. 


\section{Instrument}

As part of performance assessment in the context of the above mentioned recertification process, multisource feedback tools are used to facilitate the reflective process. Physicians collect feedback from multiple colleagues and also self-assess their performance. Physicians reflect on the obtained feedback and formulate

professional development goals, often in consultation with a trained facilitator [23,24]. In The Netherlands, one such assessment tool is the Inviting Co-workers to Evaluate Physicians - Tool (INCEPT) [22]. This tool is designed to capture various respondent groups' perspectives on physicians' professional performance and also includes a physician self-assessment questionnaire. The information is collected digitally and anonymously. The self-assessment questionnaire contains performance items to be rated as well as reflective open-ended questions to stimulate introspection. Although it could be argued that, in general, the rating of selfassessment questionnaires can differ from the ratings of respondent groups, this study only targets at the written reflections of the self-assessment and does not take the ratings of the questionnaire into account, The framework of these open ended questions is based on Lombarts' pillars of professional performance: (i) the pursuit of excellent care, (ii) humanistic practice, and (iii) accountability (see supplementary file 1). In this study, we were interested in physicians' perceptions and reflections on their own performance and improvement needs, including a reflection of their adherence to values and the necessary skills and competences. We therefore used physicians' written reflections on the following two open-ended questions: (i) what aspect(s) need(s) your (extra) attention in order to maintain or improve your performance, and (ii) when reflecting on your own performance, how do you perceive the balance between the three pillars of professional performance. These open ended questions suited our purpose in stimulating thoughts on a more practicebased level (what aspect(s) need(s) your (extra) attention in order to maintain or improve your performance?) and on a reflective level (when reflecting on your own performance, how do you perceive the balance between the three pillars of professional performance?). These two questions were preceded by a definition of professional performance and some sample key words for each of the three pillars, as described in Appendix 1. Physicians were not obliged to answer these questions and their answers did not need to be discussed with a facilitator or anyone else; the written reflections would be added to their personal portfolio for themselves to read and ponder upon.

\section{Data collection}

Data used for this study consist of physicians' written reflections on their own performance. We included all available written reflections - 786 in total - from hospital-based physicians that used the INCEPT tool between January 2016 and January 2017.

\section{Data analysis}

For the purposes of data analysis, we used a thematic analysis approach, a qualitative, independent and descriptive method particularly useful for large sets of written data [25]. It can be described as 'a method for identifying, analysing and reporting patterns (themes) within the data' [26]. The analytical process is characterized by description and interpretation, integration of manifest and latent contents and by drawing a 
thematic map that consists of the major themes and topics emerging from the data [25]. Following this approach, we focused on the content of the text, on 'what' is said more than 'how' it is said [27]. Since researchers bring their own backgrounds to the analytical process, practicing reflexivity is critical. In this reflective spirit, we provide the following contextual information: the lead author (MvdG), is currently working as CEO and management consultant, guiding physicians on performance, reflection and collaboration and also worked as a general practitioner for many years; her collaborators for this research represent various backgrounds including health sciences, education and methodology (BB), art history and clinical neuropsychology (EB), medicine and member of hospital board of directors $(\mathrm{MH})$, and health service research and medical professionalism (KL). The first author (re)coded all reflections and a total of 300 reflections were independently double-coded by a second researcher (BB). All aspects of coding were discussed until consensus was reached in order to establish trustworthiness in the interpretation of the data [28]. The lead author started with an overall inspection of all reflections to formulate a first understanding, in line with the thematic analysis approach [26]. After this orientation, the research team chose to translate the two reflective questions into a pre-defined coding template. Four themes thus originated as top-level codes: related to the first question: (i) pursuit of excellence, (ii) humanistic practice, (iii) accountability, and related to the second question, (iv) threats to optimal performance. Further analysis outlined a higher order level emerging from the theme of humanistic practice; this level was defined as the 'calling for being a doctor'. The theme 'threats' could be divided into individual aspects and work related aspects. This resulted in minimal adjustment of the initial coding template into the following topics: (i) the calling for being a doctor, (ii) translation of the calling into daily practice (comprising pursuit of excellent care, humanistic practice, and accountability of care) and (iii) threats to optimal performance (containing individual- and work-related aspects). The first author recoded previous reflections into the new template and subsequent original reflections were coded accordingly. The themes coded in the final template are shown in Table 1, including exemplar quotations. We used the qualitative data analysis software Dedoose to support the thematic analysis. 
Table 1

Coding Template with Examplar Quotations

\begin{tabular}{|c|c|c|c|}
\hline level code & $\begin{array}{l}\text { Second level } \\
\text { code }\end{array}$ & Third level code & Examplar quotations \\
\hline \multirow[t]{2}{*}{$\begin{array}{l}\text { Why: the essence } \\
\text { of being a doctor }\end{array}$} & $\begin{array}{l}\text { Doctor-patient } \\
\text { relationship }\end{array}$ & & $\begin{array}{l}\text { Giving lots of attentione and TLC [tender. } \\
\text { Loving Care], should be the basis in my } \\
\text { opinion, and doing this with optimal effort } \\
\text { (P662) }\end{array}$ \\
\hline & & & $\begin{array}{l}\text { I am motivated to help others, ever since I } \\
\text { was young; that's why I love my job! (P711) }\end{array}$ \\
\hline $\begin{array}{l}\text { How: translation } \\
\text { of the essence } \\
\text { into daily } \\
\text { practice }\end{array}$ & $\begin{array}{l}\text { Pursuit of } \\
\text { excellent care }\end{array}$ & $\begin{array}{l}\text { Gathering } \\
\text { knowledge and } \\
\text { competence }\end{array}$ & $\begin{array}{l}\text { I'm always looking to introduce the newest } \\
\text { techniques (P670) }\end{array}$ \\
\hline
\end{tabular}

It is important to study and stay up to date (P724)

Sharing knowledge Discussing complex patients or and competence complications, heart team meetings, transfer meetings: that's all part of how we work as a team (P 628)

Transferring knowledge and Teaching residents also keeps you sharp competence and up to date, their input is very valuable to me (P387)

\begin{tabular}{|c|c|c|c|}
\hline & $\begin{array}{l}\text { Humanistic } \\
\text { practice }\end{array}$ & $\begin{array}{l}\text { Attention, } \\
\text { compassion, } \\
\text { empathy }\end{array}$ & $\begin{array}{l}\text { I try my best to give my full attention in every } \\
\text { consultation (P204) }\end{array}$ \\
\hline & Accountability & Being transparent & $\begin{array}{l}\text { It gets to me when my diagnosis is too late } \\
\text { or not correct; when that happens, I take my } \\
\text { responsibility and discuss this openly with } \\
\text { my patients ( } 367)\end{array}$ \\
\hline & & Register/administer & $\begin{array}{l}\text { Registrating and administrating are part of } \\
\text { the responsibility that you have and are part } \\
\text { of your job; you have to earn the trust (P84) }\end{array}$ \\
\hline & & $\begin{array}{l}\text { Meeting } \\
\text { professional } \\
\text { standards }\end{array}$ & $\begin{array}{l}\text { It is important to do your best to meet your } \\
\text { care to current standards and conditions } \\
\text { (P65) }\end{array}$ \\
\hline \multirow[t]{4}{*}{$\begin{array}{l}\text { Threats to } \\
\text { optimal } \\
\text { performance }\end{array}$} & Work-related & $\begin{array}{l}\text { Heavy - } \\
\text { administrative- } \\
\text { workload }\end{array}$ & $\begin{array}{l}\text { I distaste these current systems (of } \\
\text { checkmarks) that complicate my job and } \\
\text { interfere with what's really important: my } \\
\text { patients ( } 1 \text { 680) }\end{array}$ \\
\hline & & $\begin{array}{l}\text { Collaboration- } \\
\text { issues }\end{array}$ & $\begin{array}{l}\text { I would like to have a more inspiring context, } \\
\text { our group is full of negativity (P218) }\end{array}$ \\
\hline & Individual & Physical wellbeing & $\begin{array}{l}\text { I do hope the arthrsos in my hands will not } \\
\text { obstruct my job (P470) }\end{array}$ \\
\hline & & Mental wellbeing & $\begin{array}{l}\text { Body and mind need maintanance; making } \\
\text { time to do so should be possible without }\end{array}$ \\
\hline
\end{tabular}




\section{Results}

\section{Participants}

We collected reflections of 786 physicians ( $56 \%$ female), aged 32 to 66 years, representing 35 different (sub-)specialties at 18 hospitals. A total of 737 physicians (94\%) completed the reflective questions, which we subsequently analysed; 38 physicians (5\%) used 'not applicable' or comparable short statements of less than 50 characters. Most physicians, however, reflected more extensively. The mean reflection length was 503 characters, ranging from 83 to 2963 characters.

\section{Overall findings}

The majority of physicians reflected on all three pillars of professional performance. They described concrete actions in terms of must do's and should do's regarding pursuit of excellence and accountability. Reflections on humanistic practice mainly triggered thoughts about the essence of being a physician. The professional performance model (Figure 1) captures how physicians perceive their professional performance. The participating physicians differentiated between their calling of being a doctor, the translation of this calling into daily practice and the threats to their performance, both on an individual and work-related level. Most salient in forming the model was the finding that physicians felt that humanistic practice was at the heart of their profession, referring to humanistic practice in terms of their calling, both on a professional level (meaning of work) as well as on a personal level (purpose in life). Physicians also experienced that their ability to perform well is under pressure, and there is a palpable threat to their ability to live up to their calling and to act as a genuinely caring practitioner. We will now describe these findings in more detail.

Why: the calling for being a doctor

Physicians perceive the doctor-patient relationship as the heart of being a physician. They describe earning a patient's trust as an important foundation for this relationship. As pointed out by the following physicians, respect, engagement, and genuine interest in the patient as a person are key components in order to earn such trust:

My motto is to be there for my patients, treat them to the best of my abilities and as respectful as possible. You should treat your patients as you would want your parents to be treated (P 426)

Being competent and trustworthy to my patients, that is what I am trying to be aware of every single time

(P 548)

I need to be intrinsically motivated, to meet the demands that people put on me when they need my care, to not disappoint the trust that they put in me (P 651) 
Many physicians describe this relationship as the reason why they wanted to become a physician in the first place and what they still consider as the most important aspect of their job. They experience this relationship as motivating and inspiring, the reason for putting effort in understanding and helping their patients, illustrated by the following statements:

Getting to know the person behind the patient creates understanding, a deeper relationship and motivation to meet the goal for the patient

(P107)

My heart sends me to the hospital with joy; patients and their families still touch and inspire me every single day and that's exactly what being a physician is all about for me

Contact with patients is the reason that I became a physician. I view all my patients as the human beings that they are and try to put myself in there position, thinking what I would want in their situation

(p 580)

Helping other people has always been very important to me, I was raised that way, and as a physician it is something that I hope to pass to all the people I work with (P 597)

The How: translation of the calling for being a doctor into daily practice

Physicians reflect on all three pillars of professional performance, i.e. (i) the pursuit of excellence, (ii) humanistic practice, and (iii) accountability in terms of concrete actions.

The pursuit of excellence; gathering, sharing, and transferring knowledge and competence

Knowledge and competence are central elements in the pursuit of excellent patient care in general. Physicians emphasize aspects as gathering new knowledge and competence for example by keeping up with new insights, attending courses or seeking new and innovative techniques:

I want the very best for every patient, meaning a perfect narcosis, without any complications and a patient waking up without nausea and pain. Although this isn't always possible, I always strive for that (P491)

I am eager to learn something new regarding my field of expertise every week (P725)

Next Generation Sequencing, that is a new technique that I will get into because it is THE new evolution in the area of molecular diagnostics 
(P773)

Consulting colleagues, asking each other for help, discussing outcome measures, and reflecting on performance are also mentioned in aspiring toward the best possible care:

We ask each other for help and consult one another very easily in my team, whether it is about medical or more ethical questions, that enhances the strength of our team

(P 128)

My group invests in reflecting on our performance since we believe that is conditional in striving for the best care for our patients

(P362)

Physicians recognize that optimal performance is enhanced by transferring knowledge through education and science:

I am very interested in the relationship between food and health and I advice colleagues on this topic

(P 413)

Our goal is to publish the results of our studies in peer reviewed journals (P 661)

Humanistic practice; compassion, empathy, and attention According to the participants, patients deserve their fullest attention at all times. As participants firmly noted, being empathic and attentive seem to be crucial conditions for a compassionate doctor-patient relationship. Physicians perceive humanistic practice as self-evident and an essential condition for being able to be a physician. Giving patients time and attention, being a good listener, and being open to patients' wishes, ideas, and fears are mentioned as important components according to the following accounts:

Compassion is self-evident to me since genuine attention for patients' wishes and concerns emerge from this compassion

(P352)

I try to give my patients the feeling that they have sufficient time to tell me their story and concerns. That is how they can confide in me and how I can give the best care to them (P 484)

When I inform patients or do a procedure, I treat the person in front of me and not a disease. My patients' perceptions matter, since every patient has the right to make a decision that suits him or her. I notice that patients value profound explanation of things so they feel they can really make a choice (P 628)

Accountability; transparency, administration and professional standards 
Physicians perceive accountability of care delivery as two-faced. They acknowledge their responsibility in and the importance of being transparent, of registering patient information as well as quality measures, and following professional standards:

I take time to inform my patients, to explain things that can happen. That is being transparent to me, being open about my actions, in order to be trustworthy for them (P 50)

I try to be open about my performance and explain why I do the things I do, so that my colleagues and patients have confidence in me (P349)

I would like to have more time to check professional standards; within my work with the fragile elderly, you deviate form guidelines regularly. However, it is instructive to check the standards, to prevent a patient from receiving 'inferior' care and to finetune the best care for this specific patient

(P 693)

However, the downside of the growth in accountability is frequently mentioned as well since physicians perceive a decline in time and attention for their patients as a result of these bureaucratic requirements.

Nowadays, I spend way too much time on administrating and registration, which has a negative effect on the time I can (and should) spend with my patients (P 76)

Registration is important, of course, but it should not take almost all of our time. It does not feel good that I cannot spent enough time with patients because of that (P 99)

\section{Threats to optimal performance}

When reflecting on their performance, many physicians describe situations that hinder them to perform to the best of their abilities. These situations either hamper their pursuit for excellence or put their purpose of being a physician under pressure. They perceive that such individual- and work related situations obstruct, and thus pose a threat to, optimal performance.

Individual aspects; physical and mental wellbeing

Physicians acknowledge the potential negative effect of low levels of vitality on their professional performance. They detect the impact of insufficient mental energy in lacking time and attention for oneself as resulting in loss of attention, inspiration, and enthusiasm during their contact with patients and colleagues. Physical inabilities are also mentioned as posing a potential threat to optimal performance. 
I should somehow keep my motivation and inspiration, in order to give the best care, but to be honest that is hard right now given my situation at home

(P 4)

I experience lack of time, miss the attention for myself and I wonder: how am I going to keep up with this and enjoy it?

(P83)

I had low levels of vitality due to a combination of a long period of hard work and physical complaints, that balance has restored because I work part-time now

Striving for the best possible care is very important for me, unfortunately, that has not been possible the last year due to my herniation

(P 682)

Work related aspects; workload and collaboration issues

The majority of physicians appoint work related factors as threats to optimal performance. They describe the negative effects of their heavy workload, and more specifically the increasing administrative tasks due to accountability and national or local policies. This leads to a lack of time for their patients, creating frustration and diminishing motivation. In particular, the purpose of being a physician and of humanistic practice is described as being under pressure by a heavy work- and administrative load.

I am forced to spend a lot of time doing non-patient- related activities. When I look deep into my heart, I must confess that I feel I do not meet the professional demands that one could expect from me

I feel that administration is taking over all over our hospital; that frustrates me and has a negative effect on my passion and inspiration

(P106)

The current heavy workload is a real threat for my vitality as a professional (P 693)

Being compassionate definitely suffers from time-constraints since adequate communication needs more time than is foreseen in the production-deals (P737)

The negative impact of hospital mergers is also mentioned as having an effect on physicians' performance.

No balance for me right now, I am easily irritated and agitated, it takes a lot of effort and energy to find stability in our new merged department (P 658) 
There are seriously disturbed relationships because of the merge, within the 'old' and the 'new' team. I feel that I am treated without any respect, therefor I will probably seek

a job somewhere else

(P 661)

Collaboration issues within the physician group such as disturbed relationships or negativity are also mentioned as hindering aspects:

I need to keep my engagement and motivation up, which is difficult for me right now since I really struggle with feeling any compassion for my colleagues

(P 484)

It isn't always easy to hang on in a team where being open and honesty are not considered a positive thing and a change to improve. My colleagues make me seem 'weak' and 'vulnerable'. I really need to work on my skills to be able to stand straight in this environment (and be appreciated)

(P 573)

\section{Discussion}

\section{Main findings}

In this study we investigated physicians' reflections on the three pillars of professional performance, defined as excellence, humanistic practice, and accountability. Humanistic practice was found to emerge as physicians' 'why,' that is, the heart of being a physician. Excellence and accountability were depicted as 'how'; a means to translate the essence of being a physician in daily practice. Humanistic practice was considered both a means as well as a state of being. Physicians report their ability to optimal performance is put under pressure by heavy workloads and collaboration issues. These threats to high performance in particular affect their ability to live up to their calling for being a genuinely caring physician.

\section{Explanation of the findings}

Our findings illustrate that physicians nowadays still sense the significance of their calling and that their motivation and inspiration primarily originates from this calling. Reflecting on their performance, they extensively reflect upon their essence - the heart - of being a physician. Physicians consider caring about patients and their families, putting patients' interests and concerns first, and gaining and deserving the patient's trust, as this essence. This is consistent with the humanistic realm of actually being with patients when they are suffering, exactly what many patients want and expect from their physician [29]. These findings confirm what has long been recognized, that is motivation is a driving force of behaviour and performance, extending out from the realm of philosophy to the psychological, behavioural and management domains [30]. The rich variety of motivation theories range form Herzberg's [31] motivation hygiene theory (hygiene factors in the context surrounding a job predict satisfaction and future motivation), Locke and Latham's [32] goal setting theory (task performance is enhanced by specifying targets to achieve) to the more modern theories as 
Ryan \& Deci's [33,34] Self Determination Theory (the nature of motivation predicts outcomes such as psychological health and wellbeing) and Bakker \& Demerouti's [35,36] Job Demands Resources Theory (performance blossoms when job resources ate widely available). In addition, this study highlights physicians also report and expose a deeper seated sense of meaning, resulting in dedication to their patients, when humanistic practice is made the focus of their clinical practice. Physicians thus experience having a calling, defined by Dik \& Duffy as a sense of purpose and meaning that this is the work that one was meant to do, reflecting the belief that the career is central part of a broader purpose in life and is used to help others [37]. Our findings underscore that physician performance still primary seems to originate from values and that the universal values of medical professionalism are deeply imbibed by physicians in their views on their profession and performance [7]. This may soften the view often put forward in health services and economic contribution, that money is regarded a motivator priority for physicians [38]. To the contrast, in this study, none of the physicians mentioned in their reflections 'money', 'income' or 'financial incentives' in relation to performance. This is in line with literature emphasizing non financial motivators like mastery and social purpose for changing physician behaviour [39]. This may be considered a reassuring finding, since professional values have long been recognized as fundamental for good patient care [1,2], and in our view still are.

In order to live up to their professional performance, physicians cultivate certain professional practices. They attend courses to stay afresh of the latest knowledge, introduce new techniques, participate in consultation and discussion with colleagues, share their knowledge, maintain transparency about choices they make and keep an adequate registration in the patients' interest, including managing electronic patient records and participating in quality assurance registries. However, our results also indicate that physicians experience threats in actually accomplishing these actions in practice. They mention that collaboration issues such as disturbed relationships, feelings of being hold back, insufficient space to voice their opinions and a lack of openness within their peer group negatively influence their performance. This is a disturbing finding, since effective teamwork is linked to quality and safety of patientcare [40,41], and indicative for wellbeing and job satisfaction [42,43]. Additionally, psychological safety and speaking up behaviour are known to be driving forces for a safe and stimulating learning environment where performance can flourish $[44,45,46]$.

Physicians furthermore express that they spend time on administration at the cost of (being with) their patients. This is consistent with international research indicating that increasing clerical burden is leading to limited face-to-face time with patients and that for every clinical hour spent on face-to-face interactions with patients, physicians spend an additional two hours on administrative tasks $[17,19]$. This worrisome finding seems to reflect the current era of marketisation in healthcare, shifting from people to processes, productivity and efficiency [16]. Physicians consider administrative tasks to be a serious threat to their performance, while time and attention for patients are known to be powerful drivers of physician satisfaction and the ability to provide high quality care $[18,47]$. Curtailing what primarily inspires physicians might eventually lead to physicians no longer having the time, energy and motivation to deliver the best possible care. Thus, a high clerical burden is challenging high performance not only by taking time from patients but also by potentially disconnecting physicians from their purpose of caring for patients [48]. Fortunately, multiple healthcare stakeholders now seem to take the adverse events of too much administration seriously. In the Netherlands, for example, the Department of Health and Welfare, the Health Care Inspectorate, and the Dutch Federation of Physicians joined hands and published a manifest to de-regulate healthcare [49]. 


\section{Strengths and Limitations}

This study provided us with the opportunity to analyse a substantial sample of written reflections from a representative group of hospital-based physicians. Our data were collected in a pre-defined format, coming with the limitation that this method could have potentially narrowed the focus and depth of the reflection process. Another point of consideration is the setting in which the study was conducted. Since the participants were all hospital-based physicians in The Netherlands, the findings reported may not be transferable to practices and physicians outside the hospital environment and/or the Dutch healthcare system. Lastly, researchers bring their own backgrounds to the analytical process, therefore this study might have been influenced by the medical and consultancy background of the principal author, being both a potential limitation and a strength. To strengthen data analysis and interpretation, we sought diversity within the background profiles of the research collaborators.

\section{Implications/ recommendations}

Since humanistic practice is considered to be at the heart of being a physician and indispensable for high quality care in the future, humanism should be at the top of physicians' priority list when practicing medicine. Because the lack in research on supporting and increasing humanistic practice in healthcare professionals, there is a need for more research on this topic [50]. In practice, physicians should pay attention to their personal well-being, since research indicates a relationship between physician well-being and the quality of patient care [51, 52]. Given their strong links to quality of care and patient safety, having an engaged physician workforce that experiences a sense of meaning is critical for healthcare organisations [53,54]. Organizational interventions directed at enabling physicians to focus on their core tasks in patient care could enhance physicians' experience of meaningful work. Best practices like the Mayo Clinics could be followed, where the creation of dedicated meeting spaces for physicians boosted engagement and dedication [55] and where funding of small groups of physicians to have a meal together and discuss topics that explored the virtues and challenges of being a physician, led to improvements in both meaning in work and burnout for participants [53]. Since peer support has always been part of how physicians deal with intense circumstances, this could be enhanced on the organizational level by formal peer support or coaching programmes $[55,56]$. Furthermore, investments could be made to create a psychologically safe environment by facilitating (peer) reflection and discussion regarding engagement, vitality, and humanistic practice. Rider et al. have recently underscored the importance of reinforcing humanistic and relational aspects of care on an organizational level [29]. Focus on decreasing the actual clinical burden will be constructive in creating such an environment. In The Netherlands for example, the Health Care Inspectorate and hospital organizations have become increasingly selective in what quality parameters should be used. Lastly, the profession could pay specific attention on aspects such as the essence of being a physician and professional values during training and in clinical practice.

\section{Conclusion}

This large inventory of physicians' reflections indicates that being a humanistic practitioner is at the heart of professional performance, referred to in terms such as calling, meaning or purpose. Physicians translate this 
calling further into everyday practice by explicit focus on striving for excellence, humanistic practice and accountability. They feel their high performance is hindered by threats deriving from a perceived extensive administrative workload as well as collaboration issues. These threats negatively affect the calling for being a doctor and hamper the ability to be a humanistic practitioner.

\section{Abbreviations}

INCEPT: Inviting Co-workers to Evaluate Physician Tool

\section{Declarations}

\section{Ethics and consent to participate}

Permission to use the INCEPT data anonymously for scientific purposes was granted in advance by the medical board, on behalf of all participating physicians, of the hospitals involved, being conform the General Data Protection Regulation Implementing Law. Prior to usage of the INCEPT tool, an informational meeting was held per institution, to inform all physicians about the tool an about the anonymized usage of the data for scientific purposes and research for any -including the current-study. The leading author was involved in this process in order to answer any questions. All physicians were subsequently part of the decision-making process to actually continue with the INCEPT tool in their hospital.

\section{Consent to publish}

Not applicable.

\section{Availability of data and materials}

Due to the sensitive nature of the raw data on which the conclusions of the manuscript rely, it is not publicly available. Please contact the authors for further information. The raw data were digitally collected and encrypted in accordance with the General Data Protection Regulation Implementing Law. The dataadministrator granted the leading author permission to use the encrypted data for the current study.

\section{Competing interests}

The authors declare that they have no competing interests.

\section{Funding}

No funding was obtained for this study.

\section{Authors' contributions}

MG was the initiator of this study, drafting the study design. All authors contributed to the study design. MG led the process of analysis and interpretation of the data. BB participated in the analysis through additional coding. $\mathrm{BB}, \mathrm{EB}, \mathrm{MH}$ and $\mathrm{KL}$ additionally contributed to interpretation of the data through discussion of and reflection on the analysis. MG wrote all the drafts, which were revised with input from all authors. All authors 
agree to be accountable for all aspects of the work in ensuring that questions related to the accuracy or integrity of any part of the work are appropriately investigated and resolved. All authors approved the final manuscript for publication.

\section{Acknowledgements}

Not applicable for this study.

\section{Author's information}

Myra van den Goor, MD, leading and corresponding author, m.vandengoor@q3consult.nl

CEO and researcher at Q3 BV, Company for Professional Development, Den Bosch, The Netherlands.

Benjamin Boerebach, PhD, benjaminboerebach@gmail.com

Consultant at the Department of Value-Based Healthcare, St. Antonius Hospital, Nieuwegein, the Netherlands.

Elisa Bindels, MSc, e.bindels@amsterdamumc.nl

PhD candidate, Center for Professional Performance \& Compassionate Care, Department of Medical

Psychology, Amsterdam University Medical Centers, University of Amsterdam, Amsterdam, The Netherlands.

Maas Jan Heineman, MD, PhD, m.j.heineman@amsterdamumc.nl

Counsellor at the Center for Professional Performance \& Compassionate Care, Department of Medical Psychology, Amsterdam University Medical Centers, University of Amsterdam, Amsterdam, The Netherlands. Former member of the hospital board of directors at the University Medical Centre of Amsterdam, Amsterdam, The Netherlands.

Kiki Lombarts, MSc, PhD, M.J.Lombarts@amsterdamumc.nl

Professor Professional Performance at the Center for Professional Performance \& Compassionate Care, Department of Medical Psychology, Amsterdam University Medical Centers, University of Amsterdam, Amsterdam, The Netherlands.

\section{References}

1. Vaismoradi $\mathrm{M} \&$ Turunen $\mathrm{H}$. Content analysis and thematic analysis: implications for conducting a qualitative descriptive study. Nursing\& Health Sciences, 2013;15:398-405.

2. Overeem K, Wollersheim HC, Arah $\mathrm{O}$ et al. Evaluation of physicians' professional performance: an iterative development and validation study of multisource feedback BMC Health Serv Res, 2012;12:80.

3. Ng SL, Kinsella EA, Friesen $\mathrm{F}$ et al. Reclaiming a theoretical orientation to reflection in medical education research: a critical narrative review. Med Educ, 2015;49:461-75.

4. Van der Meulen MW, Boerebach BCM, Smirnova A et al. Validation of the INCEPT: A Multisource Feedback Tool for Capturing Different Perspectives on Physicians' Professional Performance. J Contin Educ Health Prof, 2017;37:9-18. 
5. Royal Dutch Medical Association. Decision recertification medical specialists. Published september 2015.

6. Dutch Federation of Medical Specialists. Vision Document Medical Specialist 2025; ambition, trust cooperation. 2017. Available at:

https://www.demedischspecialist.nl/sites/default/files/FMS_visiedoc_MS2025(eng)_2017_PL_v02(Ir).pdf

7. Shanafelt TD, Dyrbye LN, Sinsky C, et al. Relationship Between Clerical Burden and Characteristics of the Electronic Environment With Physician Burnout and Professional Mayo Clin Proc, 2016;91(7): 836-848.

8. Dugdale DC, Epstein R, Pantilat SZ. Time and the patient-physician relationship. J Gen Intern Med, 1999;14:S34-40.

9. Sinsky C, Colligan L, Li L et al. Allocation of Physician Time in Ambulatory Practice: A Time and Motion Study in 4 Specialties. Ann Intern Med, 2016; 165:753-760.

10. Bonfrer I, Figueroa JF, Zheng J et al. Impact of financial incentives on early and late adopters among US hospitals: observational study. BMJ, 2018; Jan 3;360:j5622. doi: 10.1136/bmj.j5622.

11. Lombarts K. Physicians' Professional Performance between Time and Technology. 2010Uitgevers, Rotterdam, 2019. ISBN 978-94-90951-53-5.

12. Frenk J, Chen L, Bhutta ZA et al. Health professionals for a new century: transforming education to strengthen health systems in an interdependent world. Lancet, 2010;376(9756):1923-1958.

13. Ten Cate O, Snell L, Carracio C. Medical competence: the interplay between individual ability and the health care environment. Medical Teacher, 2010:32(8):669-

14. Frank JR \& Danoff D. The CanMEDS initiative: implementing an outcomes-based framework of physician competencies. Medical Teacher, 2007;29(7): 624-647.

15. Royal Dutch Medical Association. Medical Professionalism Manifesto, 2007. Available at: https://www.knmg.nl/web/file?uuid=90993000-e3b8-4713-9e8d-28a7d85eb918\&owner=5c945405-d6ca4deb-aa16-7af2088aa173\&contentid=1571.

16. Medical Board of Australia. Good Medical Practice: a Code of Conduct for doctors in Australia, issued March 2014.

17. General Medical Council. Ready for revalidation; the Good medical practice framework for appraisal and revalidation. Published March 2013, Manchester, United Kingdom.

18. Rider EA, Kurtz S, Slade S et al. The International Charter for Human Values in Healthcare: An interprofessional global collaboration to enhance values and communication in healthcare. Patient Educ Couns, 2014; 96:273-80.

19. Medical Professionalism Project. Medical Professionalism in the new millennium: a physicians' charter. The Lancet, 2002; 359:520-22.

20. Cassel CK, Hood V, Bauer WA. Physician Charter: The 10th Anniversary. Ann Intern Med, 2010;157:290-1. 
21. Askitopoulou H \& Vgontzas AN. The relevance of the Hippocratic Oath to the ethical and moral values of contemporary medicine. Part 1: The Hippocratic Oath from antiquity to modern times. European Spine Journal, 2017; Oct 27. doi:10.1007/s00586-017-5348-4. [Epub ahead of print].

22. Sritharan, K., Russel, G., Fritz, Z. et al. Medical Oaths and Declarations: A Declaration Marks an Explicit Commitment to Ethical Behavior. British Medical Journal, 2001; 323(7327):1440.

23. Royal Dutch Medical Association. Nederlandse artseneed, 2004. Available at: https://www.knmg.nl/advies-richtlijnen/knmg-publicaties/artseneed.htm

24. Relman AS. Medical Professionalism in a Commercialized Health Care Market. JAMA, 2007; 298:2668-70.

25. Lesser CS, Lucey CR, Egener B, et al. A Behavioral and Systems View of Professionalism. JAMA, 2010; 304:2732-37.

26. Braun V \& Clarke V. Using thematic analysis in psychology. Qualitative Research in Psychology, 2006;3:77-101.

27. Riessmann CK. Narrative analysis (Qualitaive Research Methods Series). 1993; California: SAGE Publications, Volume 30.

28. Pope C, Ziebland S, Mays N. Qualitative research in health care. Analyzing qualitative data. BMJ, 2000;320:114-6.

29. Rider EA, Gilligan MAC, Osterberg LG et al. Healthcare at the crossroads: the need to shape an organizational culture of humanistic teaching and practice. J Gen Intern Med, 2018;33:1092-9.

30. Steers RM, Mowday RT, Shapiro DL. The future of work motivation theory. Academy of Management Review, 2004;29(3);379-387.

31. Herzberg, F. Work and the nature of man. 1966. Cleveland: World Publishing.

32. Locke EA \& Latham GP. A theory of goal setting and task performance. 1990. Englewood Cliffs, NJ: Prentice-Hall.

33. Ryan RM \& Deci EL. Self-determination theory and the facilitation of intrinsic motivation, social development, and well-being. American Psychologist, 2000;55(1): 68-78.

34. Deci EL \& Ryan RM. Self-determination theory: A macrotheory of human motivation, development, and health. Canadian Psychology/Psychologie canadienne, 2008;49(3), 182-185.

35. Bakker AB \& Demerouti E. The Job Demands-Resources model: State of the art.

36. Journal of Managerial Psychology, 2007; 22(3):309-328.

37. Bakker AB. An evidence-based model of work-engagement. Current Directions in

38. Psychological Science, 2011;20(4): 265-269.

39. Dik BJ \& Duffy RD. Calling and vocation at work. The counseling psychologist, 2009;9;37:424-45.

40. Shortell \& Kaluzny's Health Care Management Organization, Design \& Behavior. Centage Learning, Inc. January 2011. 
41. Phipps-Taylor, M \& Shortell, SM. More Than Money: Motivating Physician Behavior Change in Accountable Care Organizations. The Milbank Quarterly, 2016;94(4), 832-864.

42. Baker DP, Day R, Salas E. Teamwork as an Essential Component of High-Reliability Organizations. Health Research and Educational Trust, 2006; DOI:10.1111/j.1475-6773.2006.00566.x

43. Weller J, Boyd M, Cumin D. Teams, tribes and patient safety: overcoming barriers to effective teamwork in healthcare. Postgraduate Medical Journal, 2014;90(1061):149-

44. Merlani P, Verdon M, Businger A, et al. Burnout in ICU caregivers: a multicenter study of factors associated to centers. American Journal of Respiratory and Critical Care Medicine, 2011;184(10):1140-6.

45. Grumbach $\mathrm{K}$ \& Bodenheimer T. Can health care teams improve primary care practice? Journal of the American Medical Association, 2004;291(10):1246-1251.

46. Edmondson A. Psychological safety and learning behavior in work teams. Administrative Sci Q, 1999;44(2):350-383.

47. Nawaz H, Edmondson A, Tzeng T et al. Teaming: An approach tot he growing complexities in health care. J Bone Joint Surg Am, 2014;96:e184.

48. Ginsburg L. "Speaking up" climate; a new domain of culture to measure and explore. BMJ Qual Saf, 2015;24:661-663.

49. Friedberg M, Chen PG, Van Bussum KR et al. Factors affecting physician professional satisfaction and their implications for patient care, health systems and health policy. Rand Health Quarterly, Winter, 2014;3(4):1.

50. Wright AA \& Katz IT. Beyond burnout - redesigning care to restore meaning and sanity for N Engl J Med, 2018;387:309-311.

51. Dutch Department of Health and Welfare. (De)Regulate Healthcare, 2018. Available at: https://www.rijksoverheid.nl/documenten/publicaties/2018/05/23/actieplan-ontregel-de-zorg

52. Lown BA, Rosen J, Marttila J. An agenda for improving compassionate care: a survey shows about half of patients say such care is missing. Health Aff, 2011; 30(9):1772-8.

53. Scheepers RA, Boerebach BCM, Arah OA et al. A systematic review of the impact of physicians' occupational well-being on the quality of patient care. International Journal of Behavioral Medicine, 2015;22(6), 683-698.

54. Panagioti M, Geraghty K, Johnson J, et al. Association Between Physician Burnout and Patient Safety, Professionalism, and Patient Satisfaction. JAMA Intern Med., 2018;178(10):1317-1331.

55. West CP, Dyrbye LN, Satele D, et al. A randomized controlled trial evaluating the effect of COMPASS (COlleagues Meeting to Promote And Sustain Satisfaction) small group sessions on physician well-being, meaning, and job satisfaction. Journal of General Internal Medicine, 2015;30:S89.

56. Shanafelt TD, Balch CM, Bechamps G, et al. Burnout and medical errors among American surgeons. Annals of Surgery, 2010;251(6):995-1000.

57. Shanafelt TD \& Noseworthy JH. Executive Leadership and Physician Well-being: Nine Organizational Strategies to Promote Engagement and Reduce Burnout. Mayo Clinic Proceedings, 
2017;92(1):129-146.

58. Hu Y, Fix ML, Hevelone ND, et al. Physicians' needs in coping with emotional stressors: the case for peer support. Arch Surg., 2012;147(3):212-217.

\section{Figures}

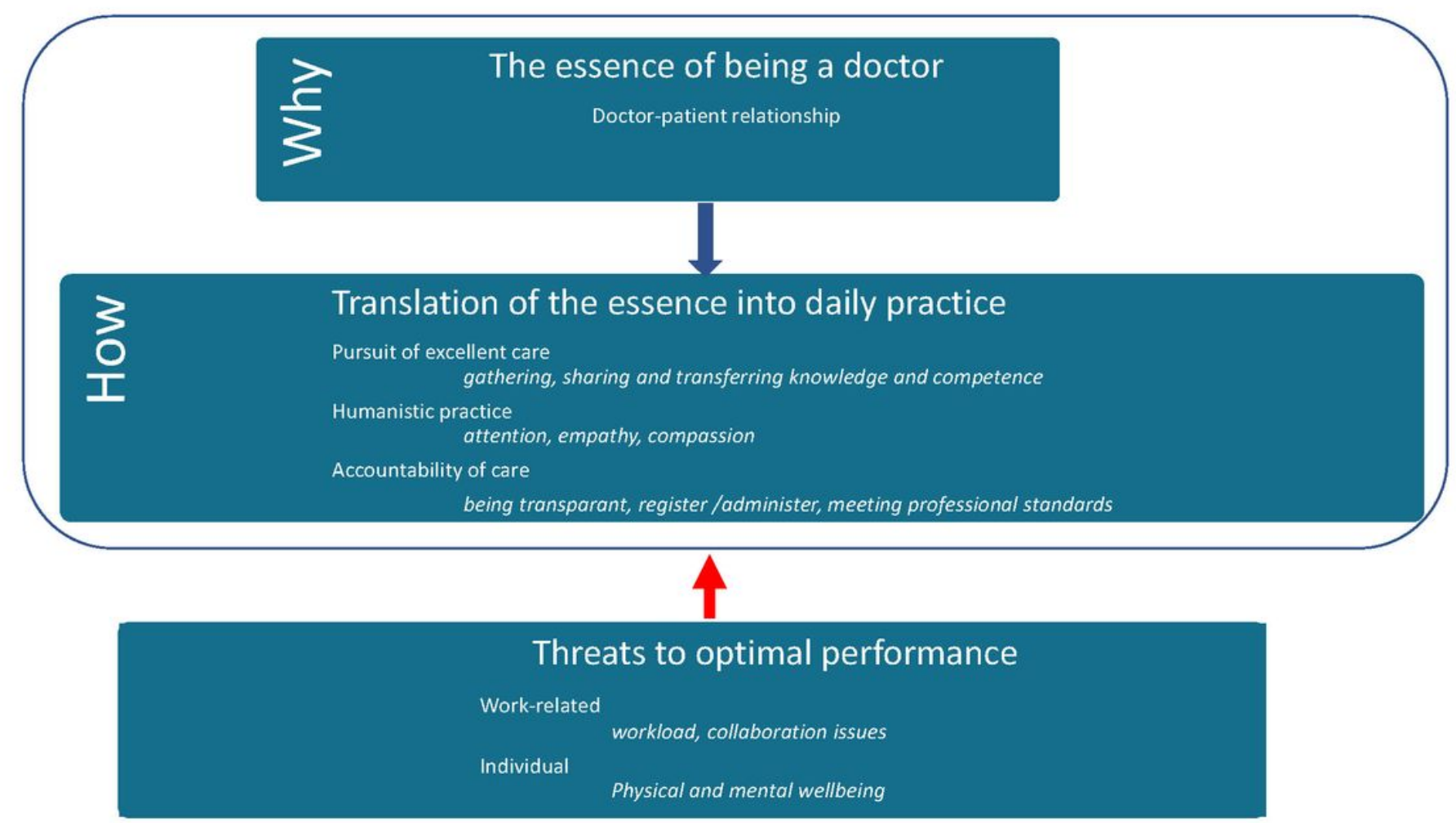

Figure 1

The Professional Performance Model

\section{Supplementary Files}

This is a list of supplementary files associated with this preprint. Click to download.

- CodingTemplatewithexamplarQuotations.pdf

- ProfessionalPerformanceModel.pdf

- Appendix1.pdf 